\title{
Relationship between depression and lung function in the general population in Korea: a retrospective cross-sectional study
}

This article was published in the following Dove Press journal: International Journal of COPD

\section{Youngmok Park \\ ji Ye Jung \\ Young Sam Kim \\ Kyung Soo Chung \\ Joo Han Song \\ Song Yee Kim \\ Eun Young Kim \\ Young Ae Kang \\ Moo Suk Park \\ Joon Chang \\ Ah Young Leem}

Division of Pulmonology, Department of Internal Medicine, Institute of Chest Disease, Severance Hospital, Yonsei University College of Medicine, Seodaemun-gu, Seoul, South Korea
Correspondence: Ah Young Leem Division of Pulmonology, Department of Internal Medicine, Institute of Chest Disease, Severance Hospital, Yonsei University College of Medicine, 50-I

Yonsei-ro, Seodaemun-gu, Seoul I20-752,

South Korea

Tel +82 I0 92439395

Fax +8223936884

Email yimayoung@yuhs.ac
Background: Lung function and depression are closely related to many chronic lung diseases. However, few studies have evaluated this association in the general population. In this study, we evaluated the relationship between lung function and depression in the general population in Korea.

Participants and methods: Data from the Ansung-Ansan cohort, a community-based cohort in Korea, were used to analyze the relationships between depression and lung function parameters. A total of 3,321 men and women aged 40-69 years were enrolled. Spirometry data included the forced expiratory volume in 1 second $\left(\mathrm{FEV}_{1}\right)$, forced vital capacity (FVC), and the $\mathrm{FEV}_{1} / \mathrm{FVC}$ ratio. Depression was defined as a score of $\geq 16$ by the Beck Depression Inventory (BDI). A propensity score analysis was conducted with the aim of reducing the bias of the retrospective study.

Results: The overall prevalence of depression in the study population was $13.1 \%(434 / 3,321$ participants). Depression was significantly more prevalent in women than in men $(P<0.001)$ and in never smokers than in ever smokers $(P<0.001)$. The group with depression was older $(P<0.001)$ and had a lower average body mass index (BMI) $(P=0.015)$ than the group without depression. The $\mathrm{FEV}_{1}(P<0.001)$, FVC $(P<0.001)$, and $\mathrm{FEV}_{1} / \mathrm{FVC}$ ratio $(P=0.022)$ were significantly lower in the group with depression than in the group without depression. After adjusting for age, sex, BMI, and smoking status, the mean $\mathrm{FEV}_{1}$ was lower in the group with a high BDI score than in the group with a low BDI score $(P=0.044)$. Using multiple linear regression analysis and adjusting for covariates, no statistically significant relationship between

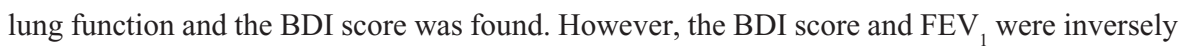
related in subjects older than 50 years $(P=0.023)$.

Conclusion: Depression is associated with decreased lung function in the general population, especially in adults older than 50 years.

Keywords: Beck Depression Inventory, COPD, depression, lung function

\section{Introduction}

Spirometry is the most frequently used method to assess lung function in patients with chronic lung disease. The forced expiratory volume in 1 second $\left(\mathrm{FEV}_{1}\right)$ gives valuable information about disease severity and progression. ${ }^{1-3}$ Spirometry also provides standardization of lung function data, which can be compared across various studies of pulmonary diseases.

The prevalence of depression has been increasing worldwide, ${ }^{4-7}$ and a relationship between pathophysiological processes of chronic lung disease and the degree of depression has been identified in previous studies. ${ }^{8-10}$ In patients with chronic lung 
disease, symptoms of depression are inversely related to lung function. ${ }^{8}$ Moreover, depression is associated with a poor prognosis in patients with obstructive lung disease, conferring a greater risk of exacerbation and possibly death. ${ }^{9}$ Depression is also directly associated with a poor quality of life and poor adherence to treatment, especially in patients with chronic lung disease. ${ }^{10}$

Similarly, patients with chronic lung disease are more likely to have depressive disorders. According to previous studies, the global prevalence of depression in patients with COPD is $\sim 40 \%$, whereas the prevalence of depression is $<10 \%$ in the general population. ${ }^{11,12}$ Activities of daily living may be significantly impaired in patients with chronic lung disease, owing to chronic pain, psychological stress, frequent exacerbations, and dependency on health care systems. Therefore, depression represents a major treatment issue in patients with chronic lung disease.

Although previous studies have examined the association between depression and lung function in patients with chronic lung disease, few studies have evaluated this association in the general population. ${ }^{13,14}$ In the previous report, restrictive lung function and obstructive lung function, compared with normal lung function, were each associated with a significantly increased likelihood of mental health problems. ${ }^{13}$ In another population-based study, depressive symptoms were associated with decreased lung function in individuals aged 55 years and older. ${ }^{14}$ In previous studies, however, the definition of depression was not based on the standardized scale with multiple-choice self-report inventory. In this study, we used a community-based cohort database to investigate whether the presence and severity of depression are related to lung function in the general population in Korea.

\section{Participants and methods Study population}

This study analyzed data from the Ansung-Ansan cohort database, which is a community-based, ongoing, prospective cohort with support from the National Genome Research Institute (Korea Centers for Disease Control and Prevention, Cheongju, Korea). This cohort is also part of the Korean Genome and Epidemiology Study, which investigates chronic disease in Korea. Detailed information regarding the study design and protocol has been previously published. ${ }^{15}$

Biennial surveys have been completed since 2001 by a population-based sample of Korean males and females aged 40-69 years in Ansung (a rural community) and Ansan (an urban community). We used data from the third survey (2005-2006) because this is when depression measurements using the Beck Depression Inventory (BDI) started being collected from participants. The present study assessed data from 7,515 eligible subjects without asthma or COPD. However, 494 participants were initially excluded because they lacked spirometry data and 3,700 participants were excluded because they lacked a BDI score. Thus, a total of 3,321 subjects were included in the final analysis (Figure 1).

The Korean Centers for Disease Control and Prevention obtained written informed consent from all study participants, and the Institutional Review Board of Severance Hospital (Seoul, Korea) approved the study protocol (4-2016-0458).

\section{Spirometry}

Lung function was measured by spirometry (VMAX2130; SensorMedics Corporation, Yorba, CA, USA). The $\mathrm{FEV}_{1}$, forced vital capacity (FVC), and $\mathrm{FEV}_{1} / \mathrm{FVC}$ ratio data were included in this analysis.

\section{Depression assessment tool}

The presence of depression was defined by the total BDI score. The BDI is one of the most widely used assessment tools of depression, evaluating a patient's emotional, cognitive, motivational, and physiological status. The BDI consists of 21 self-reporting items, and the score ranges from 0 to 63 with higher scores reflecting greater levels of depression.

The BDI was developed in $1961^{16}$ and first translated into Korean by Hahn in 1986. ${ }^{17}$ There are many opinions regarding the most appropriate cutoff points for BDI scores. In the West, a score of $\geq 15$ is generally considered to indicate depression. However, cutoff points from 16 to 21 may be more appropriate in other populations, including Koreans, as research has shown that the average BDI score is higher in these populations than in Westerners. ${ }^{18}$

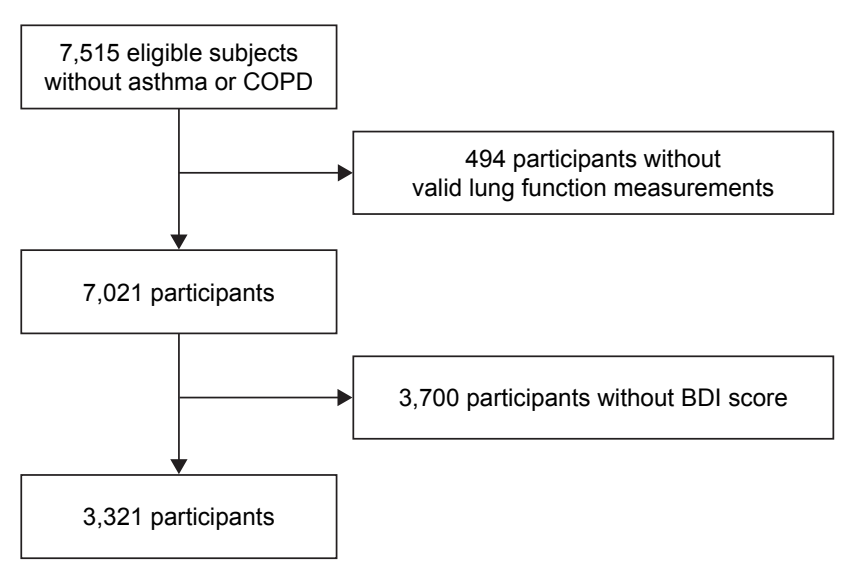

Figure I Flow chart of patient selection for the study. Abbreviation: BDI, Beck Depression Inventory. 
In the present study, a BDI cutoff score of $\geq 16$ was used to indicate depression since this cutoff has been widely used in previous studies of Koreans. ${ }^{18-20}$

\section{Statistical analyses}

Categorical variables were analyzed using Pearson's chisquared test, and continuous variables were analyzed using one-way analysis of variance. Analysis of covariance was used to estimate the adjusted means of continuous variables $\left(\mathrm{FEV}_{1}, \mathrm{FVC}\right.$, and $\mathrm{FEV}_{1} / \mathrm{FVC}$ ratio), taking into account independent variables (age, sex, body mass index [BMI], smoking, and BDI score). In the comparison of adjusted means of the $\mathrm{FEV}_{1}, \mathrm{FVC}$, and $\mathrm{FEV}_{1} / \mathrm{FVC}$ ratio, adjustment factors included age, sex, BMI, smoking status, and BDI score. Additionally, multivariate linear regression analysis was performed to investigate the relationship between BDI scores and lung function, adjusting for age, sex, BMI, and smoking status. In all analyses, $P<0.05$ (two tailed) was considered statistically significant. Correction for multiple comparisons was calculated using Bonferroni correction. SPSS software (ver 23.0; IBM Corporation, Armonk, NY, USA) was used for all statistical analyses.

\section{Propensity score matching}

A propensity score analysis was conducted with the aim of reducing the bias of the retrospective study. The propensity scores included the following variables: age, sex, BMI, and smoking status. A propensity score difference of 0.10 was adopted as the maximum caliper width for matching without depression and depression groups. Finally, 372 matched patients from each group were included in the analysis.

\section{Results \\ Baseline characteristics of the study population}

A total of 3,321 subjects were included in this study, and the baseline characteristics of the subjects are summarized in Table 1. The average age of the study participants was

Table I Baseline characteristics of the study population $(n=3,32$ I)

\begin{tabular}{|c|c|c|c|c|c|c|c|}
\hline \multirow[t]{2}{*}{ Variable } & \multirow[t]{2}{*}{$\begin{array}{l}\text { Total } \\
(\mathrm{N}=3,321)\end{array}$} & \multicolumn{3}{|c|}{$\begin{array}{l}\text { Before propensity score matching } \\
(n=3,321)\end{array}$} & \multicolumn{3}{|c|}{$\begin{array}{l}\text { After propensity score matching } \\
(\mathrm{n}=\mathbf{7 4 4})\end{array}$} \\
\hline & & $\begin{array}{l}\text { Without } \\
\text { depression } \\
(n=2,887)\end{array}$ & $\begin{array}{l}\text { Depression } \\
(n=434)\end{array}$ & $P$-value & $\begin{array}{l}\text { Without } \\
\text { depression } \\
(n=372)\end{array}$ & $\begin{array}{l}\text { Depression } \\
(n=372)\end{array}$ & $P$-value \\
\hline BDI score & $7.9 \pm 6.8$ & $5.9 \pm 4.1$ & $21.6 \pm 5.7$ & $<0.001$ & $6.1 \pm 4.3$ & $21.7 \pm 5.8$ & $<0.001$ \\
\hline Age (years) & $52.4 \pm 7.3$ & $52.0 \pm 7.1$ & $54.7 \pm 8.3$ & $<0.001$ & $55.2 \pm 8.2$ & $54.7 \pm 8.3$ & 0.463 \\
\hline Sex, male, n (\%) & $\mathrm{I}, 740(52.4)$ & $\mathrm{I}, 567(54.3)$ & $173(39.9)$ & $<0.001$ & I 54 (4I.5) & 148 (39.9) & 0.662 \\
\hline BMI $\left(k g / m^{2}\right)$ & $24.5 \pm 2.7$ & $24.5 \pm 2.7$ & $24.2 \pm 2.8$ & 0.015 & $24.4 \pm 2.7$ & $24.2 \pm 2.5$ & 0.213 \\
\hline Smoking (baseline) & & & & $<0.001$ & & & 0.385 \\
\hline Never smoker & I,947 (58.6) & I,663 (57.6) & $284(65.4)$ & & 234 (62.9) & $243(65.4)$ & \\
\hline Former smoker & $779(23.5)$ & $716(24.8)$ & $63(14.5)$ & & $67(18.0)$ & $54(14.5)$ & \\
\hline Current smoker & $594(17.9)$ & $507(17.6)$ & $87(20.0)$ & & $71(19.1)$ & $75(20.2)$ & \\
\hline Pack-years of smoking & $23.2 \pm 16.4$ & $22.6 \pm 16.0$ & $27.6 \pm 18.9$ & 0.003 & $24.0 \pm 15.9$ & $27.6 \pm 18.9$ & 0.073 \\
\hline Occupation & & & & $<0.001$ & & & 0.052 \\
\hline White collar job & $475(14.3)$ & $425(14.8)$ & $43(7.4)$ & & $42(11.3)$ & $35(9.4)$ & \\
\hline $\begin{array}{l}\text { Blue collar job br } \\
\text { unemployed }\end{array}$ & $2,857(86.0)$ & $2,455(85.2)$ & $402(92.6)$ & & $330(88.7)$ & $337(90.6)$ & \\
\hline Marriage & & & & 0.212 & & & $0.55 \mathrm{I}$ \\
\hline Single ${ }^{c}$ & $220(6.6)$ & $|8|(6.3)$ & $39(9.0)$ & & $24(6.5)$ & $33(9.0)$ & \\
\hline Married & $3,101(93.4)$ & $2,706(93.7)$ & $395(91.0)$ & & $348(93.5)$ & $339(91.0)$ & \\
\hline \multicolumn{8}{|l|}{ Underlying diseases } \\
\hline Hypertension & 394 (II.9) & $334(11.6)$ & $60(13.8)$ & 0.176 & $51(13.8)$ & $51(13.8)$ & 1.000 \\
\hline Diabetes mellitus & $|8|(5.5)$ & $153(5.3)$ & $28(6.5)$ & 0.324 & $23(6.2)$ & $24(6.5)$ & 0.889 \\
\hline Cardiovascular disease & $16(0.5)$ & $14(0.5)$ & $2(0.5)$ & 0.946 & $3(0.9)$ & $2(0.5)$ & 0.413 \\
\hline \multicolumn{8}{|l|}{ Lung function } \\
\hline $\mathrm{FEV}_{1}(\mathrm{~L})$ & $2.98 \pm 0.65$ & $3.0 I \pm 0.64$ & $2.76 \pm 0.63$ & $<0.001$ & $2.65 \pm 0.63$ & $2.84 \pm 0.62$ & 0.039 \\
\hline $\mathrm{FVC}(\mathrm{L})$ & $3.77 \pm 0.82$ & $3.80 \pm 0.82$ & $3.53 \pm 0.83$ & $<0.001$ & $3.62 \pm 0.82$ & $3.58 \pm 0.80$ & 0.659 \\
\hline $\mathrm{FEV}_{1} / \mathrm{FVC}$ & $79.4 \pm 6.1$ & $79.5 \pm 6.0$ & $78.8 \pm 6.7$ & 0.022 & $79.3 \pm 6.4$ & $78.8 \pm 6.8$ & 0.297 \\
\hline
\end{tabular}

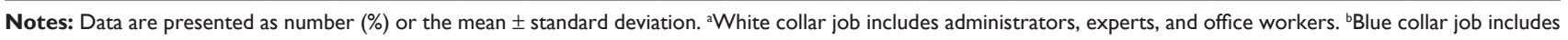
annual workers such as farmers, fishermen, and other manual workers. 'Single condition includes divorced, separated, or never married subjects. Abbreviations: BDI, Beck Depression Inventory; BMI, body mass index; FEV , forced expiratory volume in I second; FVC, forced vital capacity. 
52.4 years, and $52.4 \%$ of study population was male. The overall prevalence of depression was $13.1 \%(434 / 3,321$ participants), and the mean BDI score was 7.9.

Using the BDI score, we classified all subjects into the following two groups: those with depression and those without depression. There were statistically significant differences in age, sex, BMI, smoking status, pack-years of smoking, $\mathrm{FEV}_{1}, \mathrm{FVC}$, and $\mathrm{FEV}_{1} / \mathrm{FVC}$ ratio between the two groups. Depression was significantly more prevalent in women than in men $(P<0.001)$ and in never smokers than in ever smokers $(P<0.001)$. The group with depression was older (54.7 vs 52.0 years; $P<0.001)$ and had a lower mean BMI (24.2 vs $\left.24.5 \mathrm{~kg} / \mathrm{m}^{2} ; P=0.015\right)$ and a large proportion was unemployed or had a blue collar job than the group without depression. Additionally, the $\mathrm{FEV}_{1}(2.76$ vs $3.01 \mathrm{~L} ; P<0.001)$, FVC (3.53 vs $3.80 \mathrm{~L} ; P<0.001$ ), and $\mathrm{FEV}_{1} / \mathrm{FVC}$ ratio $(78.8$ vs $79.5 \% ; P=0.022)$ were significantly lower in the group with depression than in the group without depression.

After propensity score matching analysis, most variables were balanced between groups, but $\mathrm{FEV}_{1}$ was lower in the group with depression than in the group without depression $(P=0.039)$.

\section{Relationship between lung function and BDI score, adjusted for age, sex, BMI, and smoking}

Table 2 displays the adjusted mean $\mathrm{FEV}_{1}, \mathrm{FVC}_{\text {, and } \mathrm{FEV}_{1} /}$ FVC ratio according to the BDI score after adjusting for age, sex, BMI, and smoking status. The mean FEV 1 was lower in the group with a high BDI score than in the group with a low BDI score (2.94 vs $2.99 \mathrm{~L} ; P=0.044$ ); however, there was no statistically significant difference in the FVC $(3.74$ vs $3.77 \mathrm{~L} ; P=0.327$ ) or $\mathrm{FEV}_{1} / \mathrm{FVC}$ ratio ( 78.9 vs $79.5 \%$;
$P=0.058)$ between the two groups. The results were similar when propensity score was adjusted.

\section{Adjusted estimates of BDI score associated with lung function}

Table 3 shows the regression-adjusted estimates of BDI scores associated with lung function using multiple linear regression. After adjusting for age, sex, BMI, and smoking status, no statistically significant relationship between lung function and BDI scores was found. However, after dividing subjects based on the median age of 50 years, the BDI score and $\mathrm{FEV}_{1}$ were inversely related in the group older than 50 years $(-0.003 \mathrm{~L} ; P=0.046)$. A similar relationship was found between the FVC and BDI score in the group older than 50 years; however, this difference was not statistically significant $(-0.003 \mathrm{~L} ; P=0.103)$. After propensity score was adjusted, the trend of results was similar.

\section{Discussion}

In this study, the results imply linkages between depression and lung function among the general population in Korea. A higher BDI score was associated with a lower $\mathrm{FEV}_{1}$ after adjusting for age, sex, BMI, and smoking status. Furthermore, these results show that the severity of depression is related to the $\mathrm{FEV}_{1}$, especially in adults older than 50 years. These results are noteworthy, because only a few studies have investigated the relationship between depression and lung function in the general population.

According to previous studies, the global prevalence of depression in patients with COPD is $\sim 40 \%$, whereas the prevalence of depression is $<10 \%$ in the general population. ${ }^{11,12}$ According to Korean epidemiologic studies, the prevalence of probable depression, defined by a score of $\geq 16$ using the Center for Epidemiologic Studies Depression (CES-D) scale,

Table 2 Mean and mean differences in FEV, FVC, and FEV,/FVC (\%) by the level of BDI score adjusted for other variables

\begin{tabular}{|c|c|c|c|c|c|c|c|c|c|c|}
\hline \multirow[t]{2}{*}{ Variable } & \multirow[t]{2}{*}{ Number } & \multicolumn{2}{|l|}{ FEV $_{1}(\mathrm{~L})$} & \multirow[t]{2}{*}{$P$-value } & \multicolumn{2}{|l|}{ FVC (L) } & \multirow[t]{2}{*}{$P$-value } & \multicolumn{2}{|c|}{ FEV $_{1}$ IFVC (\%) } & \multirow[t]{2}{*}{$P$-value } \\
\hline & & $\begin{array}{l}\text { Mean } \\
(\mathrm{SE})\end{array}$ & $\begin{array}{l}\text { Mean difference } \\
(\mathrm{SE})\end{array}$ & & $\begin{array}{l}\text { Mean } \\
(\mathrm{SE})\end{array}$ & $\begin{array}{l}\text { Mean difference } \\
\text { (SE) }\end{array}$ & & $\begin{array}{l}\text { Mean } \\
\text { (SE) }\end{array}$ & $\begin{array}{l}\text { Mean difference } \\
\text { (SE) }\end{array}$ & \\
\hline \multicolumn{11}{|c|}{ Before propensity score matching $(n=3,321)$} \\
\hline BDI score & & & & 0.044 & & & 0.327 & & & 0.058 \\
\hline $0-15$ & 2,887 & $2.99(0.01)$ & Reference & & $3.77(0.01)$ & Reference & & $79.5(0.1)$ & Reference & \\
\hline $16-63$ & 434 & $2.94(0.02)$ & $0.05(0.02)$ & & $3.74(0.25)$ & $0.03(0.02)$ & & $78.9(0.2)$ & $0.6(0.2)$ & \\
\hline \multicolumn{11}{|c|}{ After propensity score matching $(\mathrm{n}=744)$} \\
\hline BDI score & & & & 0.043 & & & 0.562 & & & 0.122 \\
\hline $0-15$ & 2,887 & $2.82(0.02)$ & Reference & & $3.55(0.01)$ & Reference & & $79.4(0.1)$ & Reference & \\
\hline $16-63$ & 434 & $2.76(0.02)$ & $0.05(0.03)$ & & $3.53(0.25)$ & $0.03(0.02)$ & & $78.8(0.2)$ & $0.6(0.4)$ & \\
\hline
\end{tabular}

Notes: Data are presented as adjusted mean (SE) and mean difference (SE) unless otherwise indicated. FEV, and FVC were adjusted for age, sex, BMI, and smoking status. FEV,/FVC (\%) was not adjusted for age, sex, and smoking status.

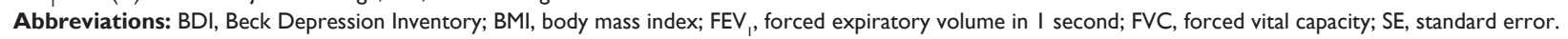


Table 3 Adjusted estimates of BDI for lung function according to multiple linear regression analysis

\begin{tabular}{|c|c|c|c|c|c|c|}
\hline \multirow{2}{*}{$\begin{array}{l}\text { Dependent } \\
\text { parameters }\end{array}$} & \multicolumn{3}{|c|}{ Before propensity score matching $(n=3,32 I)$} & \multicolumn{3}{|c|}{ After propensity score matching $(n=744)$} \\
\hline & $\begin{array}{l}\text { Estimated } \\
\text { BDI score }\end{array}$ & $\begin{array}{l}\text { Standard } \\
\text { error }\end{array}$ & $P$-value & $\begin{array}{l}\text { Estimated } \\
\text { BDI score }\end{array}$ & $\begin{array}{l}\text { Standard } \\
\text { error }\end{array}$ & $P$-value \\
\hline \multicolumn{7}{|l|}{ All } \\
\hline $\mathrm{FEV}_{1}(\mathrm{~L})$ & -0.001 & 0.001 & 0.472 & -0.002 & 0.001 & 0.107 \\
\hline $\mathrm{FVC}(\mathrm{L})$ & -0.001 & 0.001 & 0.732 & -0.001 & 0.001 & 0.455 \\
\hline $\mathrm{FEV}_{\mathrm{I}} / \mathrm{FVC}(\%)$ & -0.009 & 0.014 & 0.844 & -0.026 & 0.021 & 0.217 \\
\hline \multicolumn{7}{|l|}{ Age $\leq 50$ years } \\
\hline $\mathrm{FEV}_{1}(\mathrm{~L})$ & 0.001 & 0.002 & 0.639 & 0.001 & 0.003 & 0.682 \\
\hline $\mathrm{FVC} \mathrm{(L)}$ & 0.001 & 0.002 & 0.476 & 0.003 & 0.003 & 0.298 \\
\hline $\mathrm{FEV}_{\mathrm{l}} / \mathrm{FVC}(\%)$ & -0.012 & 0.020 & $0.56 I$ & -0.031 & 0.033 & $0.34 I$ \\
\hline \multicolumn{7}{|l|}{ Age $>50$ years } \\
\hline $\mathrm{FEV}_{1}(\mathrm{~L})$ & -0.003 & 0.001 & 0.046 & -0.005 & 0.002 & 0.022 \\
\hline $\mathrm{FVC}(\mathrm{L})$ & -0.003 & -0.002 & 0.103 & -0.004 & 0.002 & 0.150 \\
\hline $\mathrm{FEV}_{\mathrm{I}} / \mathrm{FVC}(\%)$ & -0.016 & 0.020 & 0.864 & -0.032 & 0.029 & 0.273 \\
\hline
\end{tabular}

Notes: Data are presented as adjusted mean (SE) and mean difference (SE) unless otherwise indicated. FEV, and FVC were adjusted for age, sex, BMI, and smoking status. FEV $/$ /FVC (\%) was not adjusted for age, sex, and smoking status.

Abbreviations: BDI, Beck Depression Inventory; BMI, body mass index; FEV ${ }_{1}$, forced expiratory volume in I second; FVC, forced vital capacity; SE, standard error.

was $25.3 \%-38.9 \%$ and the prevalence of definite depression (a CES-D score of $\geq 25$ ) was $8.7 \%-21.2 \% .^{21}$ Notably, the overall prevalence of depression found in the present study $(13.1 \%)$ is within the range found in previous studies.

There are many assessment tools for depression, including the CES-D scale, Hamilton Depression Rating Scale, Montgomery-Asberg Depression Rating Scale, Geriatric Depression Scale, and Patient Health Questionnaire-9. ${ }^{18}$ Here, we used the BDI because it has an established reliability and validity in a variety of different population groups and it has a high sensitivity and specificity for diagnosing depressive symptoms..$^{22-24}$ Moreover, the BDI is considered one of the most widely used self-reporting assessment tools for the severity of depression. In this study, we used a BDI cutoff score of 16, which has been previously used to indicate depression in studies of Koreans. ${ }^{18-20}$

The association between COPD and depression has been reported in several previous studies. The presence of depression is associated with worse clinical outcomes in COPD patients, as well as increased morbidity, mortality, disability, and health care expenditure. ${ }^{25-27}$ The prevalence of depression in COPD patients varies widely between studies, depending on the sampling methodology and the degree of illness severity used in the assessment of depression. ${ }^{25}$ The prevalence of depression has been reported to range from $10 \%$ to $42 \%$ in patients with stable COPD and from $10 \%$ to $86 \%$ in patients with acute COPD exacerbation. ${ }^{25,28,29}$ Furthermore, growing evidence suggests that the relationship between depression and COPD is bidirectional, meaning that depression adversely impacts the prognosis in COPD patients and the presence of COPD increases the risk of developing depression. $., 30,31$

Despite many previous reports about the relationship between COPD and depression, few studies have evaluated the correlation between lung function and depression in the general population. ${ }^{13,14}$ In a study based on a general population aged 25-74 years in the USA, obstructive lung function was associated with significantly lower overall well-being and restrictive lung function was associated with significantly lower overall well-being, general health, vitality, and selfcontrol, as well as with higher depression subscale scores. ${ }^{13}$ In that study, the General Well-Being (GWB) scale was used, which is a well-validated measure of psychological status and well-being. ${ }^{13}$ Although the GWB score is a widely accepted representation of mental health, it does not directly assess psychopathology. The BDI, which was used in our study, is considered to be more appropriate for assessing depression than the GWB scale. However, the study by Lu et $\mathrm{a}^{14}$ demonstrated an association between depressive symptoms and obstructive lung function parameters, such as the $\mathrm{FEV}_{1}$ and $\mathrm{FEV}_{1} / \mathrm{FVC}$ ratio, in older adults within the general population. In line with those results, the present study also found that depression was associated with a lower $\mathrm{FEV}_{1}$ in the general population, particularly in adults older than 50 years. However, the study by Lu et al only included older subjects, whereas the present study included subjects across a wider age range.

The mechanisms underlying the association between depression and lung function remain unclear; however, there are several possible mechanisms to consider. For example, 
decreased lung function may be related to symptoms such as dyspnea, which can lead to feelings of hopelessness, reduced physical activity, social isolation, and a sedentary lifestyle. All of these factors can be associated with an increased level of depressive symptoms. Moreover, a previous study found that the relationships between depression and lung function appear to be partly mediated by proinflammatory cytokines such as interleukin- 6 and C-reactive protein. ${ }^{14}$

The present study has several strengths. First, this is the first study to investigate the relationship between depression and lung function in the general population and not just in elderly subjects. Second, this study was based on a large community-based cohort and is therefore free of clinical selection bias from over-sampling of severe cases of diseases. Third, this analysis controlled for potentially confounding factors such as age, sex, smoking, and BMI.

The present study does have several limitations. First, it is difficult to establish a causal relationship in a cross-sectional study. Second, depression was measured by the BDI rather than a structured psychiatric interview. The BDI is a selfreport questionnaire, which may underestimate a person's degree of depression. Furthermore, too many subjects $(3,700 / 7,515$ eligible subjects) were excluded because they lacked a BDI score. There was a possibility that those subjects who were affected by severe depression could not answer the multiple questions in BDI and lacked a BDI score. Third, the BDI-I that was used in the present study might be an outdated assessment tool. The BDI-II, which was developed in 1996 based on the criteria of the Diagnostic and Statistical Manual of Mental Disorders, fourth edition, ${ }^{32}$ was first validated for use in Koreans in 2008 by Sung et al. ${ }^{33}$ Fourth, the information on the use of selective serotonin reuptake inhibitors or other medications was not fully investigated in AnsungAnsan cohort study. Fifth, the data for the spirometry of Ansung-Ansan cohort study since 2006 have not been opened to the public yet. Therefore, the data analyzed in this study were $>12$ years old.

\section{Conclusion}

We found that depressive symptoms were associated with decreased lung function in the general population and not just in patients with chronic pulmonary disease. This trend was especially prominent in subjects older than 50 years. Depression is the most common mood disorder, and respiratory diseases, such as COPD, are among the leading causes of morbidity and mortality in Korea. Therefore, regular screening of depressive symptoms, as well as referrals to psychiatrists for those with signs or symptoms of a depressive disorder, are recommended. Future studies investigating the mechanisms underlying the association between depression and lung function may have significant public health implications in terms of both primary and secondary preventions.

\section{Author contributions}

YP contributed to the acquisition of data, analysis, and drafting the article. JYJ, KSC, and JHS contributed to the data analysis. SYK, EYK, YSK, and YAK contributed to the conception and design. MSP and JC contributed to the data analysis and revising the article critically. AYL contributed to the conception, design, and revising the article critically. All authors contributed toward data analysis, drafting and revising the paper and agree to be accountable for all aspects of the work. All authors agreed to be accountable for all aspects of the work.

\section{Disclosure}

The authors report no conflicts of interest in this work.

\section{References}

1. Vogelmeier CF, Criner GJ, Martinez FJ, et al. Global strategy for the diagnosis, management, and prevention of chronic obstructive lung disease 2017 report. GOLD executive summary. Am J Respir Crit Care Med. 2017;195(5):557-582.

2. Davies JC, Alton EW. Monitoring respiratory disease severity in cystic fibrosis. Respir Care. 2009;54(5):606-617.

3. Fletcher C, Peto R. The natural history of chronic airflow obstruction. Br Med J. 1977;1(6077):1645-1648.

4. Compton WM, Conway KP, Stinson FS, Grant BF. Changes in the prevalence of major depression and comorbid substance use disorders in the United States between 1991-1992 and 2001-2002. Am J Psychiatry. 2006;163(12):2141-2147.

5. Twenge JM, Gentile B, DeWall CN, Ma D, Lacefield K, Schurtz DR. Birth cohort increases in psychopathology among young Americans, 1938-2007: a cross-temporal meta-analysis of the MMPI. Clin Psychol Rev. 2010;30(2):145-154.

6. Murphy JM, Laird NM, Monson RR, Sobol AM, Leighton AH. A 40-year perspective on the prevalence of depression: the Stirling County Study. Arch Gen Psychiatry. 2000;57(3):209-215.

7. Hidaka BH. Depression as a disease of modernity: explanations for increasing prevalence. J Affect Disord. 2012;140(3):205-214.

8. Goldbeck L, Besier T, Hinz A, et al; TIDES Group. Prevalence of symptoms of anxiety and depression in German patients with cystic fibrosis. Chest. 2010;138(4):929-936.

9. Atlantis E, Fahey P, Cochrane B, Smith S. Bidirectional associations between clinically relevant depression or anxiety and COPD: a systematic review and meta-analysis. Chest. 2013;144(3):766-777.

10. Smith A, Krishnan JA, Bilderback A, Riekert KA, Rand CS, Bartlett SJ. Depressive symptoms and adherence to asthma therapy after hospital discharge. Chest. 2006;130(4):1034-1038.

11. Demyttenaere K, Bruffaerts R, Posada-Villa J, et al; WHO World Mental Health Survey Consortium. Prevalence, severity, and unmet need for treatment of mental disorders in the World Health Organization World Mental Health Surveys. JAMA. 2004;291(21):2581-2590.

12. Yohannes AM, Willgoss TG, Baldwin RC, Connolly MJ. Depression and anxiety in chronic heart failure and chronic obstructive pulmonary disease: prevalence, relevance, clinical implications and management principles. Int J Geriatr Psychiatry. 2010;25(12):1209-1221. 
13. Goodwin RD, Chuang S, Simuro N, Davies M, Pine DS. Association between lung function and mental health problems among adults in the United States: findings from the First National Health and Nutrition Examination Survey. Am J Epidemiol. 2007;165(4):383-388.

14. Lu Y, Feng L, Feng L, Nyunt MS, Yap KB, Ng TP. Systemic inflammation, depression and obstructive pulmonary function: a population-based study. Respir Res. 2013;14:53.

15. Shin C, Abbott RD, Lee H, Kim J, Kimm K. Prevalence and correlates of orthostatic hypotension in middle-aged men and women in Korea: the Korean Health and Genome Study. J Hum Hypertens. 2004;18(10):717-723

16. Beck AT, Ward CH, Mendelson M, Mock J, Erbaugh J. An inventory for measuring depression. Arch Gen Psychiatry. 1961;4:561-571.

17. Hahn HM, Yum TH, Shin YW, Kim KH, Yoon DJ, Chung KJ. A standardization study of Beck Depression Inventory in Korea. J Korean Neuropsychiatr Assoc. 1986;25(3):487-500.

18. Yoon S, Lim J, Han C. Rating scales for measurement-based clinical practice of depression. Korean J Psychopharmacol. 2012;23(4):136-146.

19. Lustman PJ, Clouse RE, Griffith LS, Carney RM, Freedland KE. Screening for depression in diabetes using the Beck Depression Inventory. Psychosom Med. 1997;59(1):24-31.

20. Jo SA, Park MH, Jo I, Ryu SH, Han C. Usefulness of Beck Depression Inventory (BDI) in the Korean elderly population. Int J Geriatr Psychiatry. 2007;22(3):218-223.

21. Park JH, Kim KW. A review of the epidemiology of depression in Korea. J Korean Med Assoc. 2011;54(4):362-369.

22. Beck AT, Steer RA, Carbin MG. Psychometric properties of the Beck Depression Inventory: twenty-five years of evaluation. Clin Psychol Rev. 1988;8(1):77-100.

23. Park CY, Kim SY, Gil JW, Park MH, Park JH, Kim Y. Depression among Korean Adults with type 2 diabetes mellitus: ansan-communitybased epidemiological study. Osong Public Health Res Perspect. 2015;6(4):224-232.

24. Bock K, Bendstrup E, Hilberg O, Lokke A. Screening tools for evaluation of depression in chronic obstructive pulmonary disease (COPD). A systematic review. Eur Clin Respir. 2017;4(1):1332931.
25. Maurer J, Rebbapragada V, Borson S, et al; ACCP Workshop Panel on Anxiety and Depression in COPD. Anxiety and depression in COPD: current understanding, unanswered questions, and research needs. Chest. 2008;134(4 suppl):43s-56s.

26. Pumar MI, Gray CR, Walsh JR, Yang IA, Rolls TA, Ward DL. Anxiety and depression-Important psychological comorbidities of COPD. J Thorac Dis. 2014;6(11):1615-1631.

27. Dalal AA, Shah M, Lunacsek O, Hanania NA. Clinical and economic burden of depression/anxiety in chronic obstructive pulmonary disease patients within a managed care population. COPD. 2011;8(4):293-299.

28. Laforest L, Roche N, Devouassoux G, et al. Frequency of comorbidities in chronic obstructive pulmonary disease, and impact on all-cause mortality: a population-based cohort study. Respir Med. 2016;117: 33-39.

29. Lecheler L, Richter M, Franzen DP, et al. Frequency of comorbidities in chronic obstructive pulmonary disease, and simpact on all-cause mortality: a population-based cohort study. Eur Resp Rev. 2017;26(144).

30. Tetikkurt C, Ozdemir I, Tetikkurt S, Yilmaz N, Ertan T, Bayar N. Anxiety and depression in COPD patients and correlation with sputum and BAL cytology. Multidiscip Respir Med. 2011;6(4):226-231.

31. Yohannes AM, Mullerova H, Hanania NA, et al. Long-term course of depression trajectories in patients with COPD: a 3-year follow-up analysis of the evaluation of COPD longitudinally to identify predictive surrogate endpoints cohort. Chest. 2016;149(4):916-926.

32. Beck AT, Steer RA, Ball R, Ranieri W. Comparison of beck depression inventories -IA and -II in psychiatric outpatients. J Pers Assess. 1996;67(3):588-597.

33. Sung H-M, Kim J-B, Park Y-N, Bai D-S, Lee S-H, Ahn H-N. A study on the reliability and the validity of Korean version of the beck depression inventory-II (BDI-II). J Korean Soc Biol Ther Psychiatry. 2008;14(2): 201-210.
International Journal of COPD

\section{Publish your work in this journal}

The International Journal of COPD is an international, peer-reviewed journal of therapeutics and pharmacology focusing on concise rapid reporting of clinical studies and reviews in COPD. Special focus is given to the pathophysiological processes underlying the disease, intervention programs, patient focused education, and self management protocols.

\section{Dovepress}

This journal is indexed on PubMed Central, MedLine and CAS. The manuscript management system is completely online and includes a very quick and fair peer-review system, which is all easy to use. Visit http://www.dovepress.com/testimonials.php to read real quotes from published authors. 